ISSN 1991- 8690

Website: http://jsci.utq.edu.iq
الترقيم الدولي •1991 - 1991

Email: utjsci@utq.edu.iq

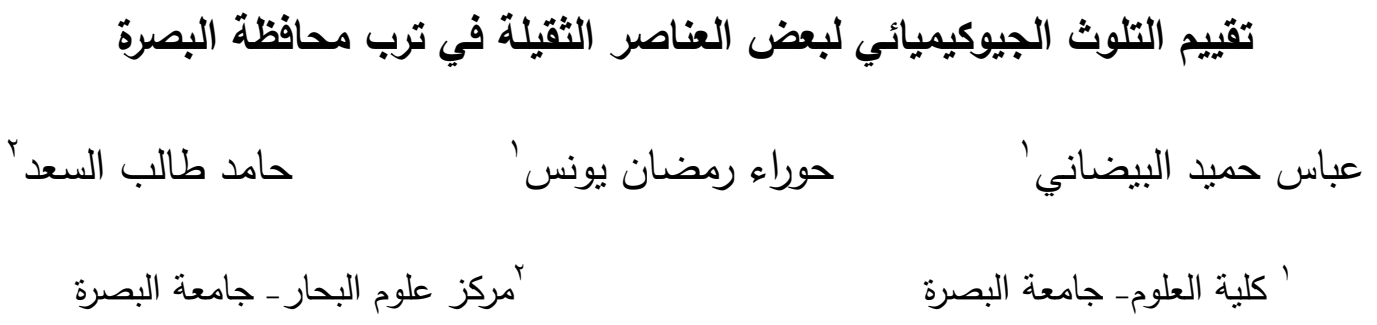

(الم|خص:

تضمنت الدراسة الحالية قياس تراكيز بعض العناصر الثقيلة (الرصاص، الكادميوم، الكوبلت، النحاس، الزنلك، النيكل، الحديد والمنغنيز) لنماذج

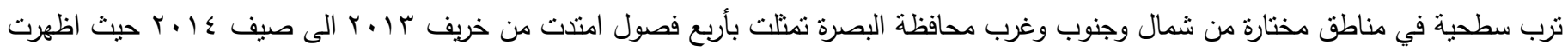

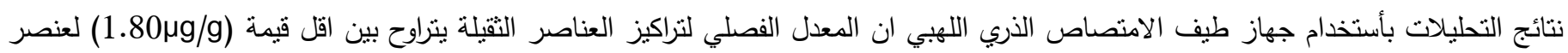

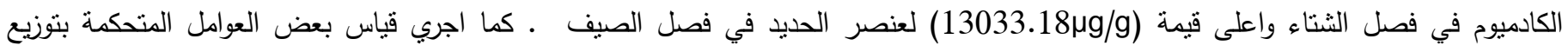
العناصر النقبلة في التربة والمتمتلة بـ(الكاربون العضوي الكلي TOC\% التوزيع الحجمي للحبيبات) والتي أظهرت ضعف العلاقة الارتباطية بين نركيز

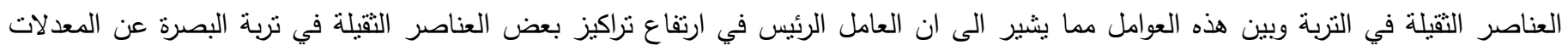

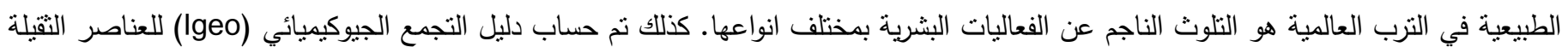

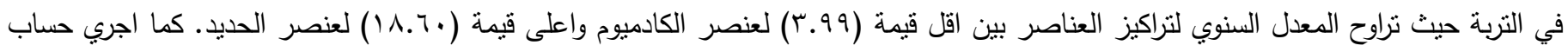

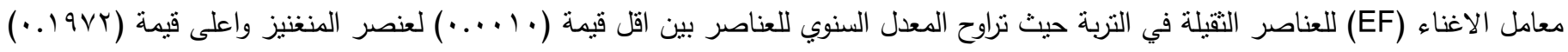

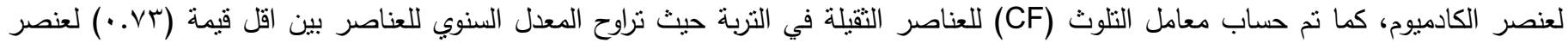

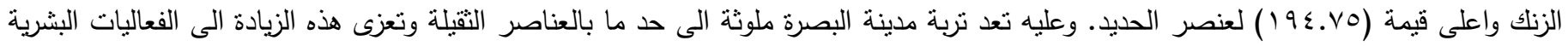
والصناعية كزيادة مركبات النقل وعمليات حرق البنزين وزيادة طرح الملوثات من المنشآت الحكومية منل المستثفيات ومعامل الطاقة الكهربائية وشركات النفط والغاز ومعمل الورق وغيرها فضلا عن استخدام الاسمدة الفوسفاتية في المناطق الزراعية، كما تعمل بعض المجمعات الصناعية على زيادة تراكيز بعض العناصر الثقيلة في التربة. الكلمات الافتتاحية: العناصر الثقلة، التزبة، الكاربون العضوي الكلي، التوزيع الحجمي للحبيبات، دليل التجمع الجيوكيميائي، معامل الاغناء، معامل

\title{
Geochemical evaluation pollution for some heavy metals in basra soil
}
Abbas Hameed Al-Bedhany ${ }^{1}$ Hawraa Ramadhan ${ }^{1}$
Hamid Talib Al-Saad ${ }^{2}$
${ }^{1}$ Coll. Of Science. Univ. Of Basrah/ Iraq
${ }^{2}$ Marin Science Centre. Univ. Of Basrah/ Iraq

\section{Abstract:}

The present study included determine concentrations of certain heavy metals (lead, cadmium, cobalt, copper, zinc, nickel, iron and manganese) of surface soils in selected areas of North, South and west of Basra governorate consisted of four seasons from autumn 2013 to summer 2014 by using Flame atomic absorption spectrum. The seasonal variation of these elements range from lowest value $(1.80 \mu \mathrm{g} / \mathrm{g})$ for cadmium in winter and the highest value $(13033.18 \mu \mathrm{g} / \mathrm{g})$ for iron in the summer. Total organic carbon TOC\% and grain size analysis where also determined and there is not correlation between them, these factors suggesting that working in high concentrations of certain heavy elements in Basra than in natural soils is pollution from human activities. Geochemical index (Igeo) where also determined that average concentration ranged from less value (3.32) for cadmium and the highest value (18.81) for iron. While the Enrichment factor (EF) range from less value (0.0005) for manganese and highest value (0.414) for cadmium. Finally Contamination factor (CF) range from less value (0.46) for zinc and the highest value (223.21) for 
iron. Basra contaminated soil with heavy elements increase is attributable to human and industrial activities such as increased transportation vehicles and burning gasoline and from other facilities such as hospitals, power plants and oil companies, as well as the use of phosphate fertilizers in agricultural areas, as well as some industrial parks to increase concentrations of some heavy metals in the soil.

Keyword: heavy metal, Soil, Total organic carbn(TOC \%), Grain size analysis, Geochemical index (Igeo), Enrichment factor (EF), Contamination factor (CF).

شملت قياس كمية الكاربون العضوي الكلي حيث اتبعت الطريقة الموصوفة في (Preer et al., 1980) والتحليل الحجمي للحبيبات المقدمة: حيث استخدم جهاز التحليل الحجمي للحبييات نوع Mastersizer 2000, Malvern Sturgeon et Chester and Voutsinou, 1981) المنبعة في (al., 1982 and Geoaccumulation Index (Igeo) Enrichment Factor (EF) في البيئة بحسب الطريقة المنبعة من قبل (Muller, 1979)، ومعامل التلوث Contamination Factor (CF) (Sarvides et al., كمعيار لتلوث الرواسب بالعناصر النقيلة

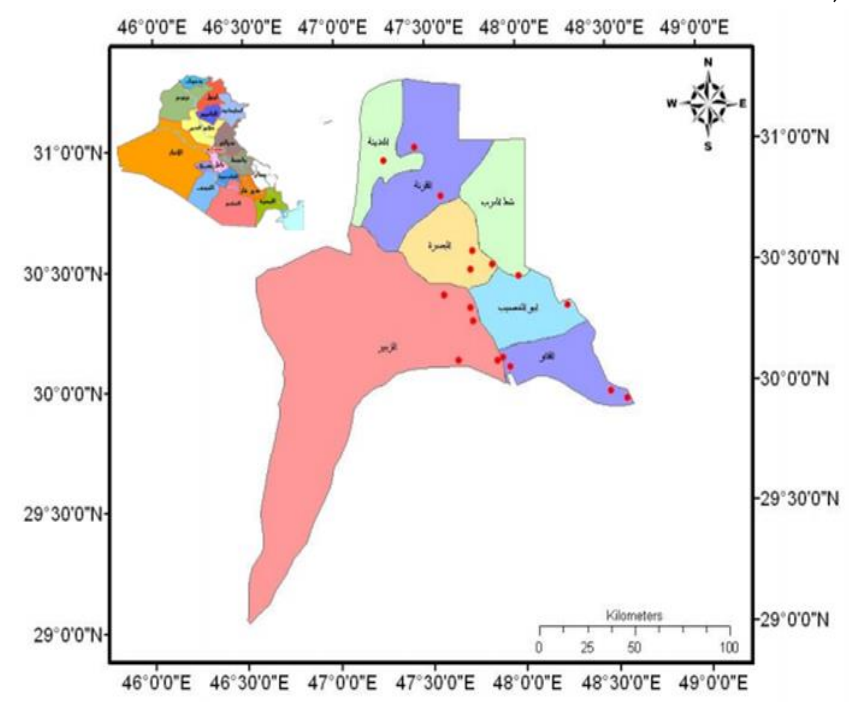

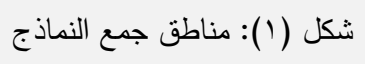

\section{النتائج والمناقثة:}

أظهرت نتائج التغيرات الموقعية والفصلية لتركيز العناصر الثقيلة

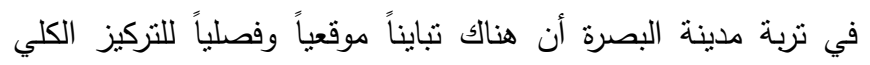

يقترن دائماً مفهوم التلوث بمفهوم البيئة إذ انه لايمكن النطرق

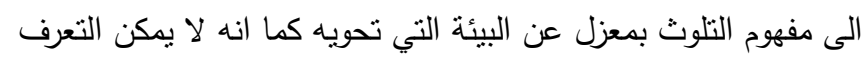

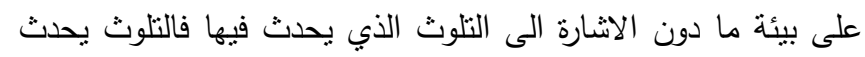

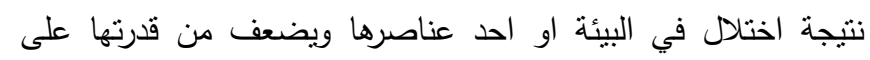

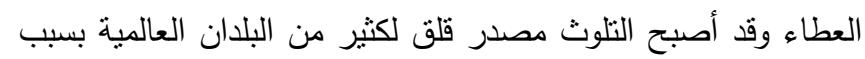

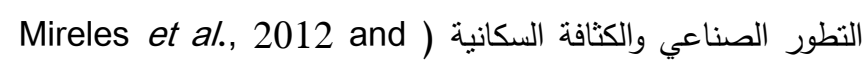
Yaylah-Abanuz, 2011 ). لقد اهتمت الدراسة بنلوث تربة مدينة البصرة إذ نم اختيارها لكونها من الترب المعرضة لثنتى انواع التلوث بسبب ما تعرضت له من حروب خلال القرن الماضي والحاضر اولاً

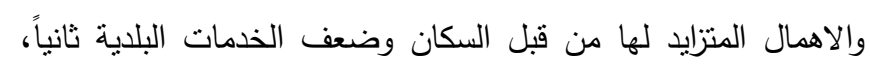

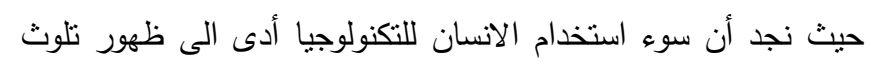

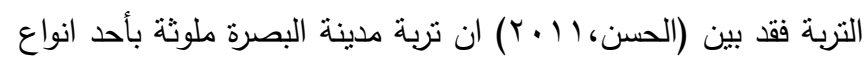

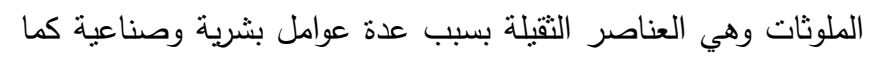
قيم (Sultan et al., 2013) مستويات تراكيز بعض العناصر الثقيلة

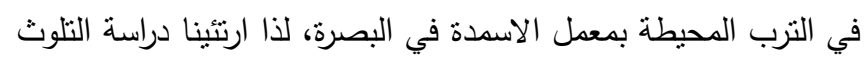

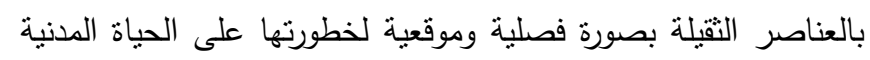

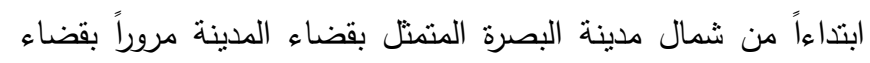

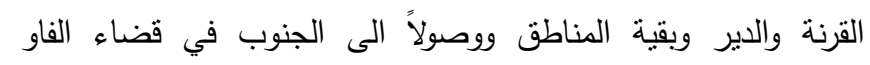

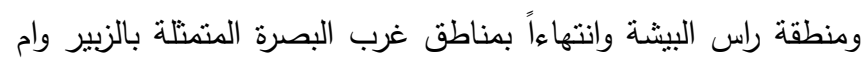
قصر وسفوان وبقية المناطق.

\section{مواد العمل وطرائقه:}

تم جمع العينات من (V V (I ) موقع شكل (l) وبصورة فصلية ولمدة

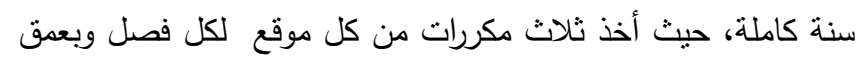

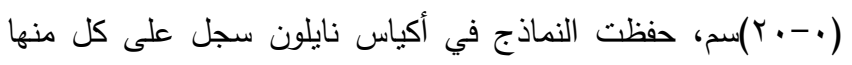

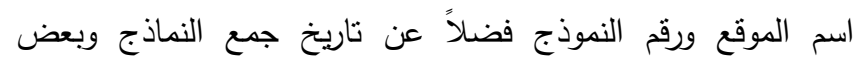
الملاحظات الحقلية ثم نقلت النماذج الى المختبر لأجراء التحاليل المختبرية. حيث اجريت بعض الفحوصات الكيميائية والفيزيائية والتي لاجئ لئي 


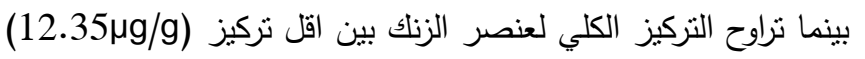

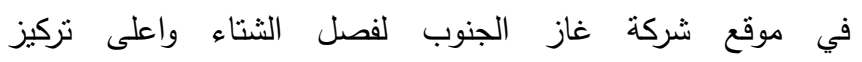

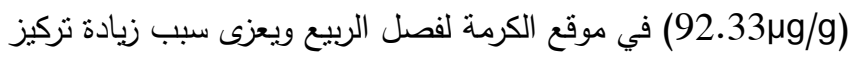
عنصر الزنك في موقع الكرمة الى وجود زيادة في العادة العضوية الناتجة من فضلات الحيوانات المتنقلة في المنطقة وكذلك زيادة الكيادة نسبة

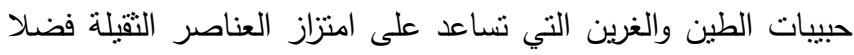

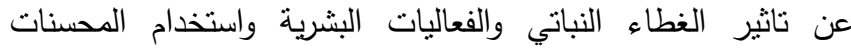

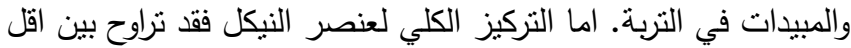

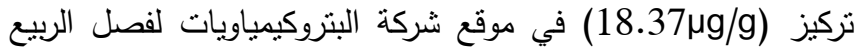

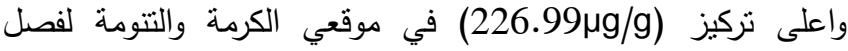
الثتاء ويعزى سبب زيادة تركيز النيكل في موقع التتومة الى قربها من فئرئ

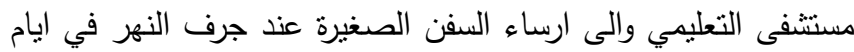

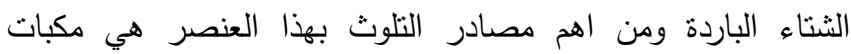

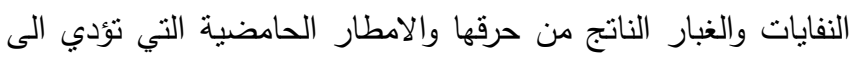

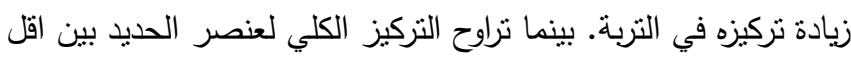
تركيز (3574.48/g/g) في موقع سفوان لفصل الربيع واعلى تركيز

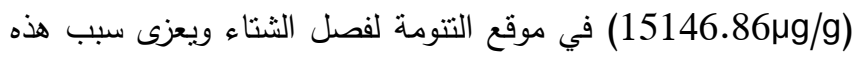
الزيادة في تركيز الحديد وبالذات في فصل الثناء الى فلة التبخر وهطول الامطار التي تجرف معها اكاسيد الحديد الى التربة من مكبات

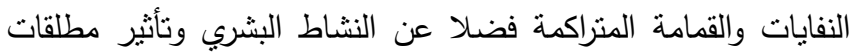

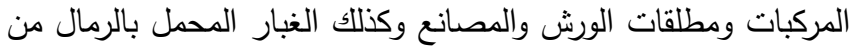
مصادر مختلفة. اما التزكيز الكلي لعنصر المنغنيز فقد تزاوح بين اقل

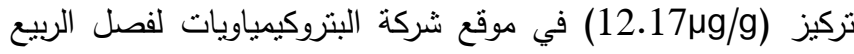
واعلى تركيز (413.29/2/g) في موقع ابوالخصيب لفصل الثتاء ويعزى سبب زيادة تركيزه في موقع ابو الخصيب الى كون المنطقة

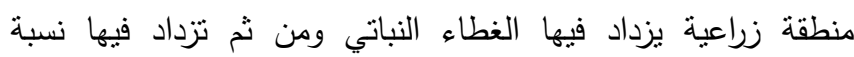

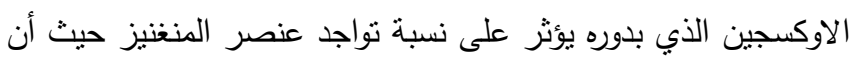

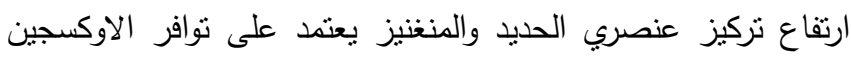
وبالعكس (Moor and Ramamoorthy, 1984).
اللعناصر الثقبلة، جدول (او r). وقد ساعدت عوامل عديدة على زيادة تراكيز العناصر الثقيلة في التربة فنجد أن أقل قيمة للتركيز الكلي

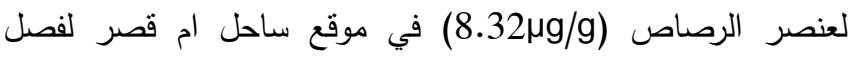
الصيف واعلى قيمة (228.14mg/g) في موقع السيبة لفصل الخريف

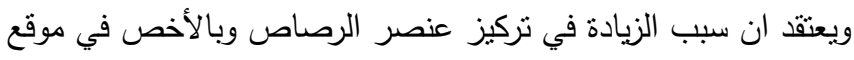

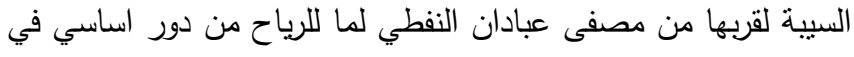

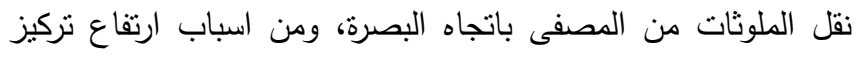

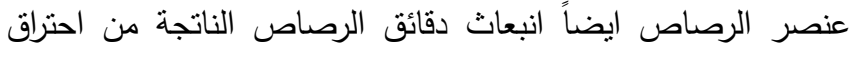

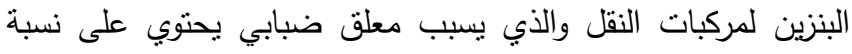

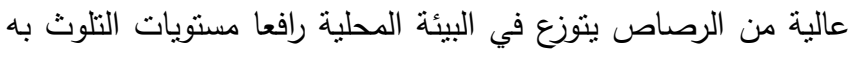

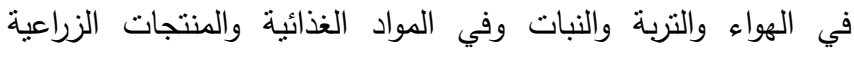
(Wilda, 1993). (ما التركيز الكلي لعنصر الكادميوم فقد تراوح بين الكين

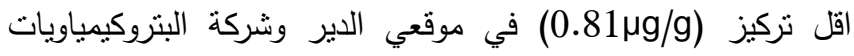

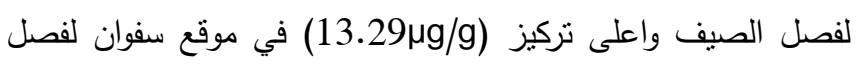

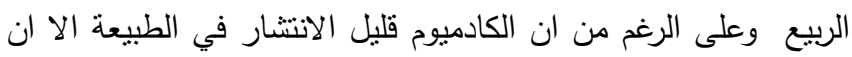

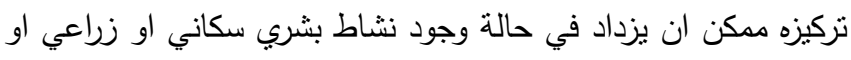

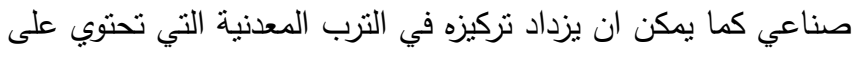

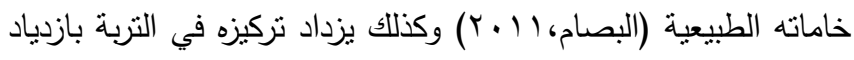
استخدام الاسمدة الفوسفاتية التي تضاف الى التربة بيينما تراوح التزكيز الكلي لعنصر الكوبلت بين اقل تركيز (2.94mg/g) في موقعي المدينة

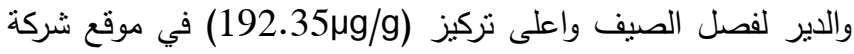

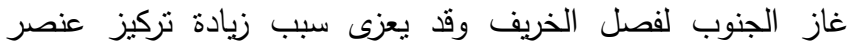
الكوبلت في موقع شركة الغاز الى بقايا الملوثات الناتجة من الابخرة المنطايرة من المعمل والتي تترسب في التزبة، كذلك تنتأثر زيادة تركيزه بعوامل عدة منها: اصل ونكوين التزبة، وعمليات التجوية، كما يتأثر التران بالفعاليات البشرية، فضلاً عن تأثير مياه الدجاري والمبازل (المالكي، المكائ

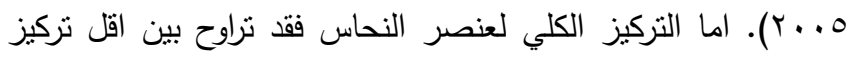

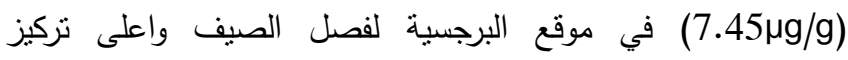

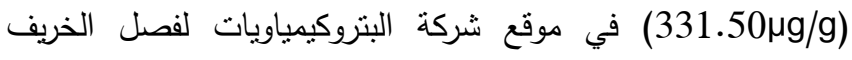

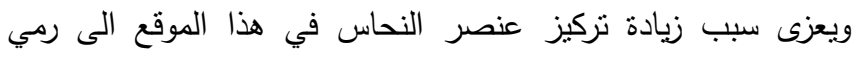

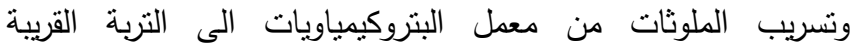
والمحيطة بالمعمل، ومما يساعد على زيادة تركيز العنصر انه في فصل الخريف تزداد الرطوبة وهذا بدوره يتيح حدوث سلسلة من التفاعلات

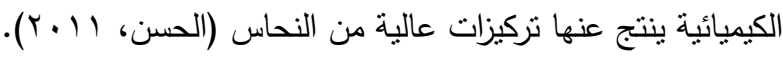


جدول (ץ): التحليل الحجمي للحبييات

\begin{tabular}{|c|c|c|c|c|}
\hline ألتسجة & 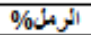 & الغرين\%\% & 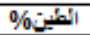 & ألهوقي \\
\hline ترين طيني & 8.12 & 76.44 & 15.44 & المئيتي \\
\hline ثرين طيني & 11.58 & 70.77 & 17.65 & 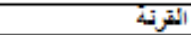 \\
\hline ثرين ربمب & 27.41 & 50.59 & 22.00 & الهير \\
\hline ترين رمبّي & 18.97 & 61.18 & 19.85 & أكريتة الكية \\
\hline ثرين طبيتب & 4.38 & 74.17 & 21.45 & شنُ الزَزير \\
\hline رمبي ثريتب & 76.63 & 20.88 & 2.49 & ألبرجسية \\
\hline رمبن ثرينب & 56.2 & 38.6 & 5.20 & 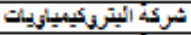 \\
\hline رملئيريذي & 76.05 & 22.04 & 1.91 & 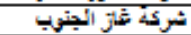 \\
\hline رمبني تريني & 78.65 & 19.44 & 1.91 & سقوان \\
\hline 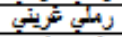 & 70.51 & 26.6 & 2.89 & ميناء خورالزيير \\
\hline ثرين طينب & 16.32 & 65.09 & 18.59 & مرفأ تحبيل الفغز \\
\hline ربلي ثريتي & 63.37 & 32.32 & 4.31 & ام تَصر \\
\hline 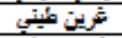 & 10.46 & 70.19 & 19.35 & التتوية \\
\hline ترين ربذب & 18.47 & 60.18 & 21.35 & ابي ألخعيب \\
\hline تُرين طِينَ & 7.42 & 69.61 & 22.97 & أسيبية \\
\hline ثرينَ طِيتِ & 6.37 & 70.71 & 22.92 & ألقأي \\
\hline تريزي طبيتي & 0.38 & 64.35 & 35.27 & راس أئيثة \\
\hline ثرين رمبذي & 32.42 & 52.53 & 15.03 & المعثل \\
\hline
\end{tabular}

اما الكاربون العضوي الكلي (TOC\%) لنماذج التربة فقد تبين ان هناك

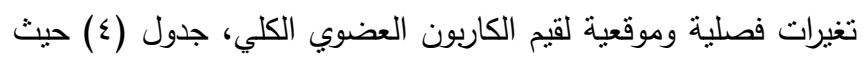

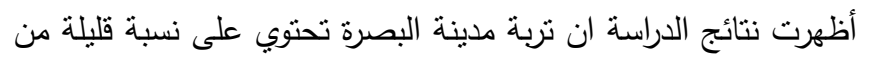

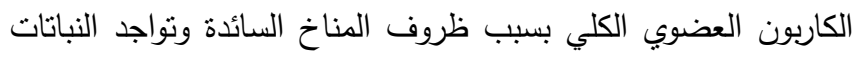
والحيوانات حيث وجد ان اعلى معدل سنوي لقيم الكاربون العضوي

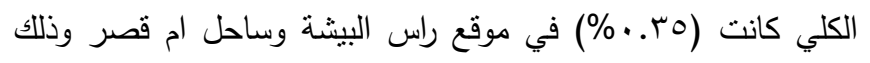

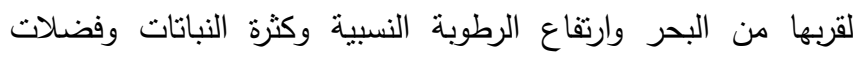
الحيوانات اما اقل معدل سنوي فكان (·r.r\%) في موقع البرجسية

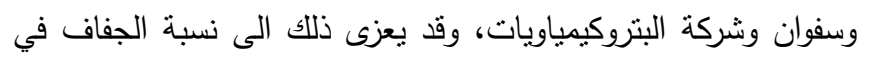

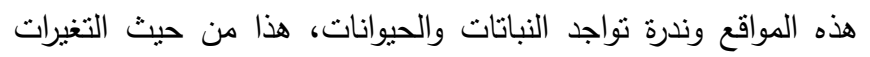
الموقعية اما من حيث التغيرات الفصلية فكان اعلى معدل لقيم الكاربون

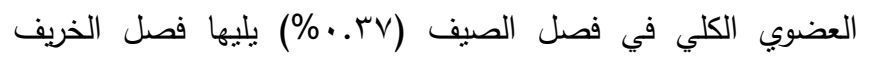

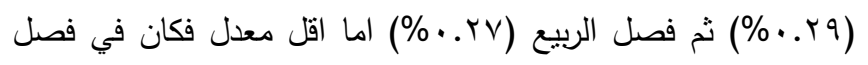

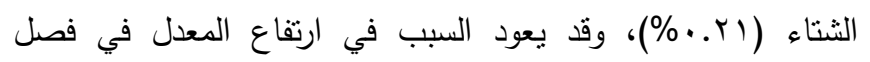
الصيف الى استخدام الاسمدة العضوية في الكثير من الترب الزراعية

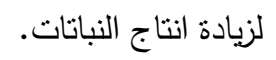

جدول (1): تراكيز العناصر النقيلة (Pb, Cd, Co, Cu) مايكروغراماغرام وزناً جافاً خلال اربعة فصول

\begin{tabular}{|c|c|c|c|c|c|c|c|c|c|c|c|c|c|c|c|c|}
\hline \multicolumn{4}{|c|}{ ثزيز غُور تلنس } & \multicolumn{4}{|c|}{ 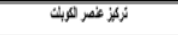 } & \multicolumn{4}{|c|}{ 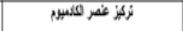 } & \multicolumn{4}{|c|}{ 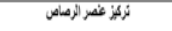 } & \multirow[b]{2}{*}{ سربِّ } \\
\hline هبذ & ريب & |نثان & كرين & هيذ & ريبي & |ن & |خرين & هبذ & 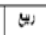 & لنداك & فرين & مبذ & ريب & |ندئ & |نرين & \\
\hline 12.41 & 19.93 & 16.55 & \begin{tabular}{|l|l|l|}
71.81 \\
\end{tabular} & 2.4 & 104.75 & 24,48 & 124.92 & 3.2 .2 & 8.86 & 1.21 & 157 & 24.9 & 8.37 & 45.77 & 91,53 & النئية \\
\hline 19.03 & \begin{tabular}{|l|}
993 \\
\end{tabular} & 26.47 & 105.23 & 5.87 & 63.64 & 24,48 & 16.16 & 2.01 & 3.2 .2 & 2.01 & 5.19 & 39.53 & 106.69 & 4993 & 1079 & الترن \\
\hline 19.85 & 43.02 & 41.36 & 83.72 & 2.4 & 64.61 & 34.27 & 140.47 & 0.81 & 8.86 & 2.01 & 425 & 37.4 & 8.31 & 60.33 & $\begin{array}{l}99.27 \\
\end{array}$ & الثير \\
\hline 19.03 & \begin{tabular}{|l|l|}
57.91 \\
\end{tabular} & 28.95 & 8557 & 16.64 & 64.61 & 12.73 & 147.95 & \begin{tabular}{|l|l|}
0.81 \\
\end{tabular} & 8.46 & 1.21 & 12.29 & 12.48 & 88,45 & 39.53 & 74.89 & 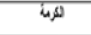 \\
\hline 1737 & 13.4 & 26.47 & 80.87 & 6.85 & 70.49 & 2345 & 149,43 & 2.42 & 9.26 & \begin{tabular}{|l}
0.81 \\
\end{tabular} & 142 & 24.96 & \begin{tabular}{|l|l|}
99.85 \\
\end{tabular} & 39.53 & 62.66 & نطازئي \\
\hline 745 & 121.61 & 14.89 & 260.29 & 490 & 60.70 & 4.90 & 107.10 & 1.21 & 10.97 & 2.01 & 5.25 & 39.53 & 87.31 & 33.36 & 76.55 & لبريبة \\
\hline 19.85 & 24.82 & 56.25 & 3150 & 10.77 & 44.166 & 392 & 141.76 & \begin{tabular}{|l|l|}
0.81 \\
\end{tabular} & \begin{tabular}{|l|l}
9.67 \\
\end{tabular} & \begin{tabular}{|l|l|} 
\\
\end{tabular} & \begin{tabular}{|l|l|}
633 \\
\end{tabular} & 14.56 & \begin{tabular}{|l|l|}
93.61 \\
\end{tabular} & 39.53 & 86.62 & 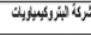 \\
\hline 12.41 & 77.16 & 9.10 & 18686 & 8.81 & 7930 & 7.83 & 19235 & 2.82 & 8.06 & 1.21 & 456 & 24.96 & 68.65 & 20.80 & 13930 & 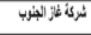 \\
\hline 15.72 & 21.51 & 14.89 & 278.65 & 3.92 & 6853 & 12.73 & 16.16 & 5.24 & 13.29 & 1.21 & 245 & 29.12 & \begin{tabular}{|l|l|}
99.85 \\
\end{tabular} & 20.80 & 20.21 & L \\
\hline 14.06 & 7.28 & 19.85 & 156.91 & 10.77 & 7538 & 2937 & 8083 & 2.82 & 9.67 & 2.01 & 7.12 & 12.48 & 79.05 & 16.64 & \begin{tabular}{|l|l|l|} 
\\
\end{tabular} & 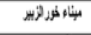 \\
\hline 1737 & 2.8 .82 & 25.64 & 60.09 & 15.66 & 9398 & 20.56 & 140.31 & \begin{tabular}{|l|l|}
3.62 \\
\end{tabular} & 10.47 & 3.2 .2 & \begin{tabular}{|l}
6.61 \\
\end{tabular} & 37.4 & $101.93 \mid$ & 3536 & 66.15 & 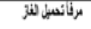 \\
\hline 11.58 & 15.72 & 20.68 & 121.11 & 8.81 & 7832 & 11.75 & 4926 & 2.82 & 9.67 & 2.42 & 5.69 & 832 & \begin{tabular}{|l|l|} 
\\
\end{tabular} & 45.77 & 67.48 & سالفا بأشر \\
\hline 27.30 & 8.27 & 37.23 & 138.22 & 8.81 & 76.36 & 34.27 & 168.70 & 3.2 & 8.46 & 1.21 & 3.22 & \begin{tabular}{|l|l|}
18.72 \\
\end{tabular} & 99,85 & 45,7 & $\begin{array}{l}10976 \\
\end{array}$ & ترنية \\
\hline 22.4 & 13.24 & 35.57 & 199.53 & 392 & 7930 & 1566 & 13.21 & 3.2 .2 & 7.25 & 2.82 & 258 & 31.20 & 79.05 & 47.85 & 78.38 & اليو الفيبي \\
\hline 15.72 & 16.55 & 26.47 & $16,1.99$ & 30.35 & 73,43 & 14.69 & 18.29 & 4.83 & 10.97 & 1.61 & 688 & 20.80 & 99.77 & 27.04 & 28.14 & لسئi \\
\hline 19.03 & 13.24 & 23.99 & $291 / 2$ & 10.77 & 70.49 & 2154 & 99,43 & 4.43 & 9.67 & 2.01 & 338 & 14.56 & \begin{tabular}{|l|l|}
9.17 \\
\end{tabular} & 31.4 & 190.55 & لتر \\
\hline 14.89 & 13.24 & 2.2 .4 & 2233 & 8.81 & 6951 & 12.73 & 133.38 & 3.2 .2 & 9.26 & 2.01 & 4.01 & 22.88 & 99.77 & 10.40 & 62.66 & راسن لئية \\
\hline 16.79 & 33.48 & 26.28 & 160,01 & 9.50 & 72.79 & 1831 & 133.4 & 280 & 9.07 & 1.80 & 522 & 24.35 & 99.80 & 36.34 & 10596 & vel \\
\hline
\end{tabular}

جدول (ץ): تراكيز العناصر الثقيلة (Zn, Ni, Fe, Mn) مايكروغراماغرام وزناً جافاً خلال اربعة فصول

\begin{tabular}{|c|c|c|c|c|c|c|c|c|c|c|c|c|c|c|c|c|}
\hline \multicolumn{4}{|c|}{ 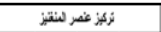 } & \multicolumn{4}{|c|}{ 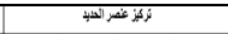 } & \multicolumn{4}{|c|}{ 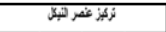 } & \multicolumn{4}{|c|}{ 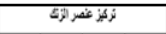 } & \multirow[b]{2}{*}{ 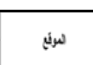 } \\
\hline ميذ & | & & | غرين | & هذب & ريبي & & نرينذ & | مين | مي | & נي & & كرينة & هب & & & فرين & \\
\hline 109.16 & \begin{tabular}{|l|l|}
110.93 \\
\end{tabular} & 288.7 & 50.90 & 14029.83 & 865694 & 10187.27 & 1146626 & $\mid 120.71$ & 48.351 & 162.70 & \begin{tabular}{|l|l|l|} 
& \\
\end{tabular} & 21.66 & 91.92 & 35.23 & 4835 & نائز \\
\hline 73.48 & 98.76 & 36.21 & 18666 & 13223.34 & 6673.96 & 1149.19 & 1106321 & \begin{tabular}{|l|l|}
90.53 \\
\end{tabular} & \begin{tabular}{l|l}
36.43 & 1 \\
\end{tabular} & 14039 & 65.98 & 48,80 & 68.4 & $\begin{array}{ll}5.0 .25 \\
5\end{array}$ & 53.45 & ترنة \\
\hline 91 & 15399 & 346.83 & 18759 & 1329,30 & 1002.2 .05 & 12812.28 & 1259988 & 19990 & \begin{tabular}{l|l}
38.05 & 1 \\
\end{tabular} & 178.4 & 6.655 & 31.79 & 8382 & 42.276 & 6.201 & st \\
\hline 68.34 & 112.200 & 30.57 & 162.13 & 12768.71 & 888939 & 11438.4 & 132766.64 & 91.85 & 48.552 & 26.69 & 7138 & 33.41 & 92,33 & 41.51 , & 70.95 & هرية \\
\hline 6.76 & 79.57 & 225.28 & 11289 & 13488.08 & 168 & 883 & 1314738 & 125.96 & $\begin{array}{ll}36.94 & 1 \\
\end{array}$ & 170.57 & 6,35 & 29.16 & 77.14 & 48395 & 5334 & نان \\
\hline 0 & 82.31 & 146.97 & 79.19 & 11952.28 & 94950 & 801 & 297 & 101.13 & 38.05 & 76.10 & 4.61 & 17.21 & 74.51 & 12.412 & 20.09 & لبرجهية \\
\hline 7882 & 12.17 & 149.92 & 95:11 & 9857.15 & 471385 & 13113.87 & 1844 & 8791 & 18371 & 102.34 & 46.71 & 2349 & 67.2 & $24.70^{7}$ & 78.59 & 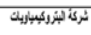 \\
\hline 42.59 & 93.61 & 90.80 & 89 & 1332281 & 03 & 15 & $\sqrt{4}$ & 6228 & 2887 & 6692 & 43.04 & 2592 & 66.61 & 12.25 & 4.79 & 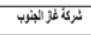 \\
\hline & $9 ., 55$ & \begin{tabular}{|l|l|}
322.49 & 1 \\
\end{tabular} & 12394 & 1324.62 & 3574.48 & 11114,40 & 1249951 & \begin{tabular}{|l|l|}
10997 \\
\end{tabular} & 48.551 & 190.25 & 8555 & 22.07 & 62.7 & 43946 & 68995 & - سرن \\
\hline 95 & 1029 & 340.74 & 191.71 & 13330.58 & 7651.162 & 1255536 & \begin{tabular}{|l|l|}
1319207 \\
\end{tabular} & 60.36 & 27.551 & \begin{tabular}{|l|l|}
19156 \\
\end{tabular} & 75.05 & 352.23 & 7593 & 48.998 & 86.01 & 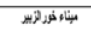 \\
\hline 9.48 & 8.12 & \begin{tabular}{|l|l|}
34.48 & 2 \\
\end{tabular} & o1 & 13398.71 & 11 & \begin{tabular}{|l|l|}
13069.19 \\
\end{tabular} & 1191866 & $\mid \begin{array}{lll}131.21 \\
\end{array}$ & 40.67 & 15482 & 52.48 & 28.35 & 76.13 & $\begin{array}{ll}4.44 \\
7\end{array}$ & 79,05 & اكتعزي نقز \\
\hline 88.65 & 7.23 & 285.041 & 151,65 & 13141.50 & 9193.12 & \begin{tabular}{|l|l|}
13192.07 \\
\end{tabular} & 1348.08 & 72.16 & 3.111 & 1855.10 & 76.63 & 20.85 & 67.83 & 4.2118 & 88.19 & ساكندارئر \\
\hline 39 & 89.87 & $389.89^{2}$ & 232.71 & 13934.89 & 18750.03 & 15146.86 & 1330935 & 119,40 & 3.112 & 22699 & 9289 & 71.27 & 68.4 & 44.10 & 74.75 & ترنية \\
\hline 103.4 & $100.63 \mid$ & 413.292 & 24.81 & 12802.22 & 84334 & 1444.30 & 1176786 & 6692 & 4.611 & 191.56 & 88.70 & 40.90 & 80.79 & 4.952 & 21.06 & بير الكبي \\
\hline 101.10 & \begin{tabular}{|l|l|}
73.22 \\
\end{tabular} & 321.551 & 189.28 & 1301893 & 7852.69 & 6970.24 & 10047.64 & 74.99 & $\begin{array}{lll}4986 & 1 \\
\end{array}$ & 131.7 & 53.11 & 28.55 & 76.4 & $\begin{array}{l}50.42 \\
\end{array}$ & 3926 & 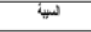 \\
\hline+ & 6680 & $36.655^{2}$ & 215.58 & 1341.16 & 8176.62 & .18 & 526 & 80.4 & 3936 1 & 12996 & \begin{tabular}{|l|l|}
5931 \\
\end{tabular} & 33.41 & 63.38 & 52.64 & 58.64 & آن \\
\hline 63.65 & 76.29 & \begin{tabular}{|l|l|}
302.26 & 1 \\
\end{tabular} & 18535 & 13288.13 & 36 & 23 & 97 & 80.4 & 32.801 & 156.14 & 61.11 & 28.75 & 67.63 & 43.94 & 3349 & 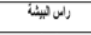 \\
\hline 82.18 & 88.01 & 292.75 & 16,50 & 13033.18 & 7880.94 & 10902.82 & 1203923 & 94.16 & 39901 & 158.14 & 65.13 & 31.81 & 74.2.2 & 40.28 & 5794 & we \\
\hline
\end{tabular}

كما بينت نتائج التحليل الحجمي للحبييات لنماذج التربة ان تربة البصرة

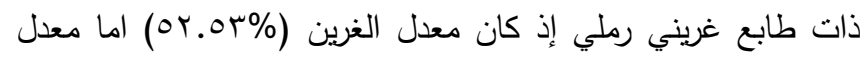

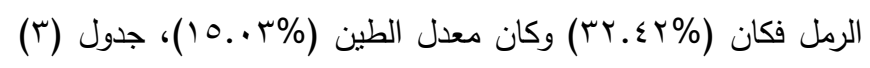

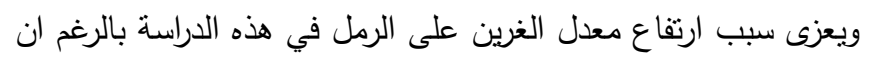

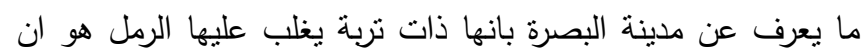

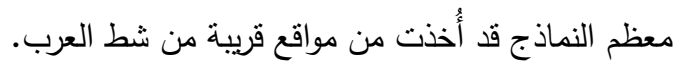


في الاراضي الزراعية القريبة من موقع الدراسة، اما عنصري الكوبلت

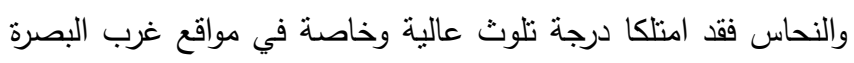
المتمتلة بشركة غاز الجنوب والبتروكيمياويات والتي تطرح بمخلفاتها الى الترب المجاورة للشركة دون معالجة. وكذلك كان لعنصري النيكل والزنك درجة تلوث عالية حيث امتلكا اعلى القيم في مواقع الكرمة والمدينة على التوالي ويعزى السبب في ذلك الى استخدام الاسمدة والمبيدات فضلاً عن مياه الصرف الصحي. اما عنصري الحديد والمنغنيز فقد امتلكا درجة تلوث عالية جداً كما في موقعي التتومة وابو

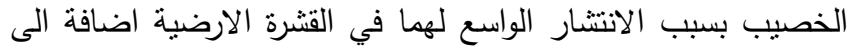
المخلفات البشرية والصحية. وهذا ساعد على عدم اعتماد اي عينة كعينة مرجعية وذللك بسبب عمليات التلوث الكبيرة الحاصلة نتيجة تذخل الانسان لذا اعتمد على تركيز العناصر الثقيلة في القترة

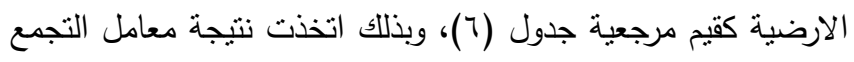
الجيوكيميائي الترتيب النالي:

$\mathrm{Fe}>\mathrm{Mn}>\mathrm{Ni}>\mathrm{Cu}>\mathrm{Zn}>\mathrm{Co}>\mathrm{Pb}>\mathrm{Cd}$

جدول (ך): المعدلات السنوية لقيم دليل التجمع الجيوكيميائي Igeo للعناصر الثقيلة في نربة مدينة البصرة

\begin{tabular}{|c|c|c|c|c|c|c|c|c|}
\hline \multicolumn{8}{|c|}{ 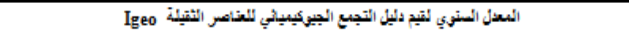 } & \multirow{2}{*}{ السوتي } \\
\hline Mn & $\mathrm{Fe}$ & $\mathrm{Ni}$ & $\mathrm{Zn}$ & $\mathrm{Cu}$ & $\mathrm{Co}_{0}$ & $\mathrm{Cd}$ & $\mathrm{Pb}$ & \\
\hline 16.41 & 18.65 & 12.31 & 10.97 & 9.85 & 9.02 & 4.16 & 9.00 & ألدينة \\
\hline 16.45 & 18.61 & 12.01 & 11.32 & 10.07 & 9.19 & 3.67 & 9.33 & 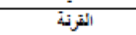 \\
\hline 16.72 & 18.79 & 12.26 & 11.24 & 10.70 & 9.01 & 3.64 & 9.28 & ألدير \\
\hline 16.36 & 18.67 & 12.33 & 11.32 & 10.67 & 9.30 & 3.82 & 8.64 & 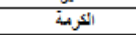 \\
\hline 16.07 & 18.52 & 12.21 & 11.16 & 10.05 & 9.26 & 3.32 & 8.86 & ثن الزيير \\
\hline 15.58 & 18.62 & 11.72 & 10.24 & 10.76 & 8.37 & 3.90 & 9.01 & 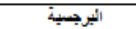 \\
\hline 15.15 & 18.38 & 11.53 & 10.93 & 11.11 & 8.56 & 3.73 & 8.76 & 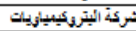 \\
\hline 15.39 & 18.64 & 11.39 & 10.51 & 10.49 & 9.06 & 3.89 & 8.78 & 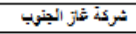 \\
\hline 16.28 & 18.37 & 12.39 & 11.05 & 10.43 & 8.84 & 4.07 & 9.11 & ستوان \\
\hline 16.45 & 18.71 & 11.94 & 11.40 & 10.74 & 9.28 & 4.30 & 8.20 & ميناء شروالزيير \\
\hline 16.50 & 18.73 & 12.15 & 11.26 & 10.16 & 9.56 & 4.57 & 9.00 & مرفذأن تحبيل الغنز \\
\hline 16.25 & 18.80 & 12.07 & 11.13 & 10.02 & 8.71 & 4.29 & 8.42 & سمحل ادتصر \\
\hline 16.74 & 18.81 & 12.40 & 11.51 & 10.36 & 9.53 & 3.83 & 9.01 & التترية \\
\hline 16.74 & 18.74 & 12.21 & 10.94 & 10.47 & 8.88 & 4.01 & 9.01 & ابو الخعيب \\
\hline 16.42 & 18.40 & 11.98 & 11.06 & 10.35 & 9.56 & 4.42 & 9.12 & أسيبية \\
\hline 16.31 & 18.62 & 11.94 & 11.21 & 10.51 & 9.22 & 4.20 & 9.04 & القأز \\
\hline 16.23 & 18.13 & 11.95 & 10.93 & 10.30 & 9.06 & 4.13 & 8.34 & راس ائيشة \\
\hline 16.24 & 18.60 & 12.05 & 11.07 & 10.41 & 9.08 & 3.99 & 8.88 & المبغل أعند \\
\hline
\end{tabular}

اما معامل الاغناء لتراكيز العناصر التقيلة والتي اعتمدت على تركيز

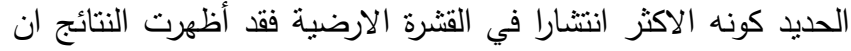
تربة مدينة البصرة تمتلك اقل ما يمكن من درجات الاغناء بالعناصر الثقيلة جدول (V) وقد يعود السبب في قلة قيم معامل الاغناء بالرغم من قيم التلوث العالي بدلالة دليل التجمع الجيوكيميائي الى التراكيز العالية لعنصر الحديد. حيث اتخذت نتيجة معامل الاغناء التزتيب
جدول (ع): المعدلات الفصلية والسنوية لقيم الكاربون العضوي الكلي TOC $\%$

\begin{tabular}{|c|c|c|c|c|c|c|c|c|c|}
\hline السنري \% أمغل & \% & 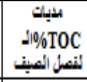 & \% أسنل & 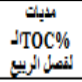 & أسغل & 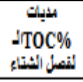 & \% أسنل & 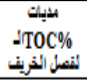 & المهني \\
\hline 0.32 & 0.43 & $0.45-0.42$ & 0.30 & $0.32-0.29$ & 0.21 & $0.22-0.20$ & 0.32 & $0.34-0.29$ & المبنية \\
\hline 0.31 & 0.41 & $0.43-0.39$ & 0.29 & $0.30-0.28$ & 0.22 & $0.25-0.20$ & 0.31 & $0.32-0.30$ & القرنة \\
\hline 0.29 & 0.40 & $0.42-0.38$ & 0.26 & $0.28-0.24$ & 0.20 & $0.23-0.17$ & 0.29 & $0.33-0.26$ & الديلي \\
\hline 0.32 & 0.38 & $0.40-0.37$ & 0.31 & $0.33-0.29$ & 0.25 & $0.27-0.24$ & 0.34 & $0.36-0.31$ & أكرئ \\
\hline 0.31 & 0.40 & $0.42-0.38$ & 0.28 & $0.30-0.26$ & 0.24 & $0.27-0.22$ & 0.30 & $0.31-0.29$ & ثن ثأزئ \\
\hline 0.20 & 0.28 & $0.30-$ & 0.18 & $0.22-0.15$ & 0.12 & $0.13-0.11$ & 0.20 & $0.22-0.18$ & البرجبية \\
\hline 0.20 & 0.30 & $0.32-0.28$ & 0.19 & $0.21-0.18$ & 0.11 & $0.13-0.10$ & 0.19 & $0.23-0.16$ & شركة التبريكيبنازيكات \\
\hline 0.21 & 0.27 & $0.28-0.26$ & 0.21 & $0.23-0.19$ & 0.15 & $0.17 \cdot 0.13$ & 0.22 & $0.24-0.20$ & شركي ثناز الجنري \\
\hline 0.20 & 0.31 & $0.33-0.27$ & 0.17 & $0.18-0.16$ & 0.13 & $0.15-0.14$ & 0.18 & $0.20-0.17$ & سفران \\
\hline 0.33 & 0.39 & 0.41 & 0.33 & $0.35-0.30$ & 0.25 & $0.27-0.22$ & 0.33 & $0.35-0.31$ & بيثاء ثري الزيير \\
\hline 0.29 & 0.36 & $0.37-0.35$ & 0.28 & $0.29-0.27$ & 0.20 & $0.21-0.19$ & 0.32 & $0.33-0.30$ & 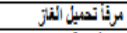 \\
\hline 0.35 & 0.41 & 0.43 & 0,35 & 0.37 & 0.26 & $0.29-0.25$ & 0.39 & 0.35 & سأدل أدئر \\
\hline 0.30 & 0.39 & 0.40 & 0.30 & 0.32 & 0.20 & $0.22-0.19$ & 0.30 & 0.27 & أتزيكية \\
\hline 0.32 & 0.42 & 0.45 & 0.31 & $0.32-0.30$ & 0.23 & $0.25-0.21$ & 0.33 & $0.36-0.29$ & 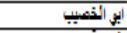 \\
\hline 0.32 & 0.42 & $0.44-0.40$ & 0.29 & $0.33-0.25$ & 0.24 & $0.26-0.22$ & 0.32 & $0.34-0.30$ & أسييك \\
\hline 0.34 & 0.43 & 0.44 & 0.33 & $0.37-0.31$ & 0.28 & $0.29-0.27$ & 0.30 & $0.32-0.28$ & الشاز \\
\hline 0.35 & 0.43 & $0.46-0.41$ & 0.32 & $0.34-0.30$ & 0.29 & $0.31 \cdot-0.28$ & 0.35 & $0.37-0.32$ & \\
\hline & & 0.37 & & 0.27 & & 0.21 & & 0.29 & يول القعبيا. \\
\hline
\end{tabular}

كذللك نم حساب دليل التجمع الجيوكيميائي لتراكيز العناصر والتي

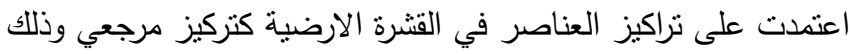

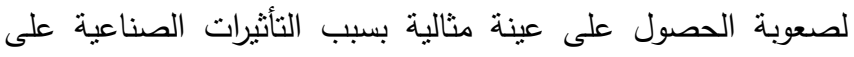
البيئة، حيث أظهرت نتائج دليل التجمع الجيوكيميائي للعناصر التقيلة في منطقة الدراسة وذلك بحسب تصنيف (Muller, 1979) جدول (0)، ان تربة مدينة البصرة ذات تلوث عالي بالعناصر الثقيلة حيث تجاوزت معظم هذه العناصر الحد الاقصى لقيم درجات التلوث. جuller, جول (0): تصنيف التزبة حسب دليل التلوث الجيوكيميائي 1979)

\begin{tabular}{|c|c|c|}
\hline ريف الترية أمسرئنة & تصت & Igeo \\
\hline تلهي تأبي & 6 & 5 | \\
\hline 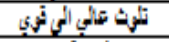 & 5 & $5-4$ \\
\hline 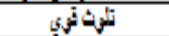 & 4 & $4+3$ \\
\hline 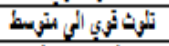 & 3 & $3-2$ \\
\hline تلزي شتهبة & 2 & 2.1 \\
\hline 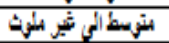 & 1 & 1.0 \\
\hline 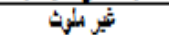 & 0 & عنز ين 0 \\
\hline
\end{tabular}

فنجد ان عنصر الرصاص امتلك قيم اعلى من الحد الاعلى للاليل

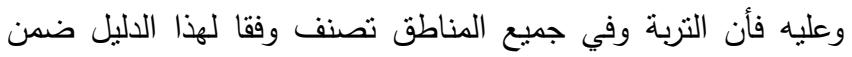
مدى التلوث العالي بالرصاص (strongly polluted) مما يؤكد تأثنير الملوثات البشرية والصناعية التي تتعرض لها البصرة. اما عنصر الكادميوم الذي اعطى درجة تلوث تراوحت بين تلوث منوسط الى تلوث

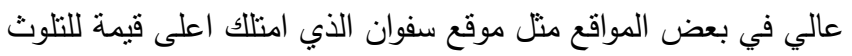
بالكادميوم وقد يعزى السبب في ذلك الى استخدام المبيدات والاسمدة 
جدول (^): المعدلات السنوية لقيم معامل التلوث CF للعناصر الثقيلة في تربة مدينة البصرة

\begin{tabular}{|c|c|c|c|c|c|c|c|c|}
\hline \multicolumn{8}{|c|}{ 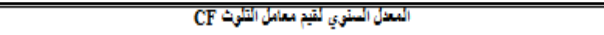 } & \multirow[t]{2}{*}{ السونغ } \\
\hline Mn & $\mathrm{Fe}$ & $\mathrm{Ni}$ & $\mathrm{Zn}$ & $\mathrm{Cu}$ & $\mathrm{C}_{0}$ & $\mathrm{Cd}$ & $\mathrm{Pb}$ & \\
\hline 1.69 & 196.89 & 5.03 & 0.70 & 0.55 & 6.43 & 34.77 & 4.46 & المينيتة \\
\hline 2.01 & 192.84 & 4.14 & 0.79 & 0.73 & 6.46 & 20.73 & 5.42 & القرتن \\
\hline 2.20 & 215.43 & 5.16 & 0.79 & 0.85 & 6.06 & 26.56 & 5.08 & الثيز \\
\hline 1.81 & 200.15 & 5.49 & 0.85 & 0.87 & 6.05 & 37.94 & 3.86 & الكرية \\
\hline 1.45 & 185.44 & 4.98 & 0.74 & 0.63 & 6.31 & 23.17 & 4.05 & نـ الزّير \\
\hline 0.99 & 192.34 & 3.25 & 0.46 & 1.84 & 4.44 & 30.91 & 4.27 & أبرجين \\
\hline 0.94 & 172.89 & 3.20 & 0.69 & 1.97 & 5.02 & 30.69 & 4.19 & شركة البتريكيبيزينات \\
\hline 0.83 & 197.05 & 2.52 & 0.54 & 1.30 & 7.21 & 27.74 & 4.53 & شركنة ثنز الجنوب \\
\hline 1.73 & 179.59 & 5.37 & 0.71 & 1.51 & 6.28 & 36.98 & 6.25 & ستوان \\
\hline 1.97 & 207.51 & 4.43 & 0.88 & 1.21 & 4.91 & 36.04 & 2.99 & بيناء خهرالزيير \\
\hline 2.03 & 208.95 & 4.74 & 0.82 & 0.58 & 6.77 & 39.87 & 4.30 & مرةأ تصيل الفغز \\
\hline 1.67 & 217.65 & 4.60 & 0.79 & 0.77 & 3.70 & 34.32 & 3.43 & ساحل ام تصر \\
\hline 2.35 & 223.21 & 5.92 & 0.92 & 0.96 & 7.21 & 26.85 & 4.90 & التمرئ \\
\hline 2.42 & 210.74 & 4.90 & 0.67 & 1.01 & 5.73 & 26.45 & 4.23 & ابي الخعيب \\
\hline 1.90 & 168.25 & 3.94 & 0.70 & 1.01 & 6.17 & 38.99 & 6.68 & السيية \\
\hline 1.96 & 194.30 & 3.86 & 0.75 & 1.58 & 5.06 & 32.49 & 6.08 & الشأز \\
\hline 1.75 & 147.45 & 4.13 & 0.63 & 1.24 & 5.66 & 30.85 & 3.46 & راس أييئن \\
\hline 1.75 & 194.75 & 4.45 & 0.73 & 1.09 & 5.85 & 31.49 & 4.60 & المعل العبد \\
\hline
\end{tabular}

وعموما فأن التفاوت في نركيز العناصر التقيلة للاراسة الحالية مع الدراسات الاخرى يعزى الى التفاوت في نوعية الترب المختارة اضافة الى حجم النفايات المنزلية والصحية وكمية الملوثات الصناعية وغيرها،

جدول (9).

جدول (9): مقارنة تراكيز العناصر في الدراسة الحالية بالد(مايكروغراماغرام)

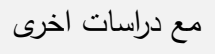

\begin{tabular}{|c|c|c|c|c|c|c|c|c|c|}
\hline سرنّ & PD & $\mathrm{Ni}$ & $\mathrm{Cu}_{\mathrm{u}}$ & $c d$ & $\bar{c}_{0}$ & Ita & $\mathrm{Fe}_{\mathrm{f}}$ & 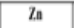 & كنار \\
\hline 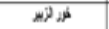 & 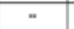 & $4666-9.13$ & $756-217.3$ & - & 21984196 & 351.5 .50 .6 & 69660.79863 & 271.56 .45 & ALSadetaL,2016 \\
\hline برب لبرو & - & 9.2.633 & 383.16 .63 & - & - & $\$ 962.418 .6$ & - & - & N-Sudet aL, SW67 \\
\hline 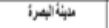 & 39.4 & 209 & 169 & is & 188 & - & 2590.9 & - & 2007 2010 \\
\hline 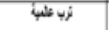 & 590 & 210 & 190 & 12 & $\overline{-}$ & 200 & 200 & 290 & ASTM, 20107 \\
\hline نسلرانبرأ & $\overline{-}$ & 5923:207/3 & $6.18-14.2$ & $9.79-19.65$ & 486.431 & 91,65 -1115 & $=$ & $\overline{-}$ & Rathem, NWO \\
\hline t4 & $15-128$ & 28.18 & - & $1+42$ & - & - & $150426 \% 8$ & 80.156 & Kamedim dzL, 2010 \\
\hline 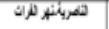 & $5,3-120$ & 8.482 .5 & 9.4013 & 0.100 .5 & $\overline{-}$ & - & $1450-196$ & $15+3100$ & سئ النران 2010 \\
\hline شئأهرن & $41.597,4$ & \begin{tabular}{|l|}
$N 9.152 .1$ \\
\end{tabular} & 36.495 & $\overline{-}$ & 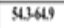 & - & 4942351300 & - & لسن 2011 \\
\hline 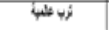 & 27 & 29 & 389 & $0 . A 1$ & 11.3 & 188 & $\overline{-}$ & $N$ & Kabuat-Peadiax, VII \\
\hline هُرب لبهرأ & 25 & 8,13 & 17.11 & 3 & - & 36.29 & $\$ 8.14$ & 39.99 & تلت 2011 \\
\hline 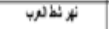 & 40.13 & sis & 30.15 & $\$ 8$ & 41.13 & - & 417089 & - & لكرانى 2011 \\
\hline 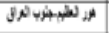 & 3123.36 .1 & 788288.95 & 16.05 .21 .14 & $\overline{-}$ & $\overline{-}$ & $=$ & 51484.5660 .1 & $\bar{*}$ & 2011 (4) \\
\hline 24 & 129.24 .15 & 2.40105 & 40.175 & 0.050 .75 & $\overline{-}$ & $=$ & $=$ & 115.369 .7 & 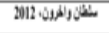 \\
\hline 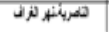 & 24.4 & 673 & 26 & 087 & - & - & - & - & 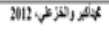 \\
\hline 24 & 128.43 & $=$ & 60.71 & 2.05 & $11 / 3$ & 181 & 8158 & 2352 & 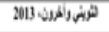 \\
\hline تكري & 2566 & 8.16 & $16: 28$ & 5 & 2023 & 402531 & $\overline{-}$ & $37 \cdot 1 \mathrm{M}$ & 2013 2013 \\
\hline هُرب لرو & 7.06 & - & 5.9 & - & - & - & 2465 & 7.10 & Al.Sabah, 2013 \\
\hline 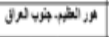 & - & - & - & 20.48 & 406? & $500-688$ & - & $50-120$ & N-Bidangy, 2013 \\
\hline منيكأبرنأ & $83228 \times 14$ & 18.72 .269 & 7AS.311.5 & 281.13.19 & 2941923 & 12.174 .13 .2 & $3574+15168$ & 12.35 .92 .313 & 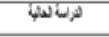 \\
\hline
\end{tabular}

\section{الاستتناجات:}

لوحظ من خلا الدراسة ان هناك اختلافات موقعية وفصلية لتراكيز العناصر الثقيلة حيث وجد ان نربة مدينة البصرة تعاني من
$\mathrm{EFCd}>\mathrm{EFPb}>\mathrm{EFCo}>\mathrm{EFNi}>\mathrm{EFCu}>\mathrm{EFZn}>$ EFMn

وبذلك نلاحظ ان عنصر الكادميوم والرصاص والكوبلت كانت اكثر اغناءاً من غيرها بسبب مصادر التلوث المتمثلة باحتراق وقود المركبات وحرق النفايات اضافة الى الملوثات التي تطرحها المنشآت الحكومية والمستشفيات ومحطات الكهرباء وغيرها.

جدول (V): المعدلات السنوية لقيم معامل الاغناء EF للعناصر التقيلة في تربة مدينة البصرة

\begin{tabular}{|c|c|c|c|c|c|c|c|}
\hline \multicolumn{7}{|c|}{ 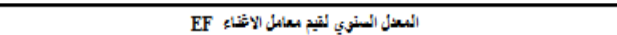 } & \multirow{2}{*}{ ائموتي } \\
\hline Mn & $\mathrm{Ni}$ & $\mathrm{Zn}$ & $\mathrm{Cu}$ & $\mathrm{C}_{0}$ & $\mathrm{Cd}$ & $\mathrm{Pb}$ & \\
\hline 0.0009 & 0.0061 & 0.0040 & 0.0026 & 0.0144 & 0.1907 & 0.0245 & السينية \\
\hline 0.0011 & 0.0050 & 0.0044 & 0.0034 & 0.0145 & 0.1143 & 0.0311 & أقرنة القة \\
\hline 0.0010 & 0.0055 & 0.0039 & 0.0037 & 0.0117 & 0.1355 & 0.0244 & الديزي \\
\hline 0.0009 & 0.0065 & 0.0046 & 0.0042 & 0.0124 & 0.2025 & 0.0211 & 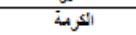 \\
\hline 0.0009 & 0.0132 & 0.0046 & 0.0030 & 0.0140 & 0.1553 & 0.0255 & شغ الزيير \\
\hline 0.0005 & 0.0040 & 0.0026 & 0.0086 & 0.0091 & 0.1703 & 0.0227 & البريبة البيا \\
\hline 0.0005 & 0.0042 & 0.0051 & 0.0096 & 0.0132 & 0.2644 & 0.0322 & شرئ البتريكيبنائياك \\
\hline 0.0005 & 0.0032 & 0.0028 & 0.0058 & 0.0139 & 0.1429 & 0.0223 & شرئ غنز الجنهرب \\
\hline 0.0011 & 0.0076 & 0.0058 & 0.0072 & 0.0191 & 0.4146 & 0.0483 & ستران \\
\hline 0.0009 & 0.0049 & 0.0046 & 0.0057 & 0.0108 & 0.2041 & 0.0172 & بيناء خمرائزيير \\
\hline 0.0009 & 0.0052 & 0.0042 & 0.0026 & 0.0143 & 0.2139 & 0.0229 & مرزأ تحبيل الغنز \\
\hline 0.0008 & 0.0049 & 0.0038 & 0.0031 & 0.0077 & 0.1755 & 0.0169 & سماحل ادتصر \\
\hline 0.0010 & 0.0058 & 0.0045 & 0.0037 & 0.0142 & 0.1527 & 0.0255 & 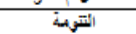 \\
\hline 0.0011 & 0.0053 & 0.0036 & 0.0043 & 0.0123 & 0.1431 & 0.0219 & ايب الخعبي \\
\hline 0.0013 & 0.0062 & 0.0046 & 0.0055 & 0.0150 & 0.2411 & 0.0409 & 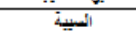 \\
\hline 0.0011 & 0.0049 & 0.0041 & 0.0067 & 0.0110 & 0.1869 & 0.0322 & الثقائر \\
\hline 0.0017 & 0.0090 & 0.0054 & 0.0076 & 0.0165 & 0.2444 & 0.0265 & راس أيسيثة: \\
\hline 0.0010 & 0.0060 & 0.0043 & 0.0051 & 0.0132 & 0.1972 & 0.0268 & أنسيزل أعلدا \\
\hline
\end{tabular}

كما تم حساب معامل التلوث لتراكيز العناصر التقيلة والتي اعتمدت على تراكيز العناصر القياسية فقد أظهرت النتائج ان تربة مدينة البصرة ذات تلوث قليل الى شديدة التلوث جدول (8) وهذه النتيجة تتباين مع ما أظهرته نتائج دليل التجمع الجيوكيميائي بكون تربة مدينة البصرة ذات تلوث عالي بالعناصر الثقيلة بسبب الاعتماد على تراكيز العناصر الثقيلة القياسية في القشرة الارضية في احتساب معامل التلوث، حيث اظهر كل من عنصر الرصاص والكوبلت والنحاس والنيكل تلوث قليل في بعض المواقع منل ساحل ام قصر وميناء خور الزبير والكرمة وغيرها الى شديد التلوث في مواقع اخرى منل القرنة وسفوان وشركة غاز الجنوب، اما عنصري الزنك والمنغنيز فأظهرت تلوث قليل الى عالي في معظم المناطق بينما كان هناك ثلوث شديد بعنصري الحديد والكادميوم. وبذلك اتخذت نتيجة معامل التلوث الترنيب التالي: $\mathrm{CFFe}>\mathrm{CFCd}>\mathrm{CFCo}>\mathrm{CFPb}>\mathrm{CFNi}>\mathrm{CFCu}>$ CFMn $>$ CFZn 


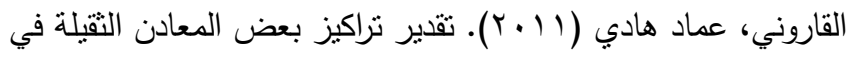

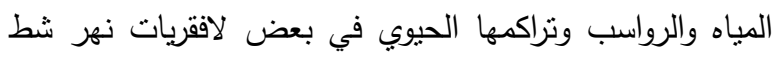

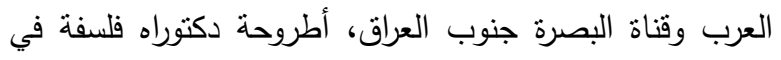

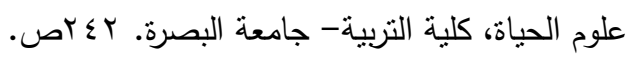

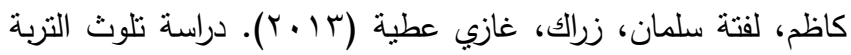

بالعناصر النقيلة في منطقة تكريت، مجلة تكريت للعلوم الصرفة،

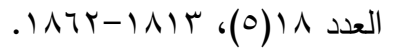

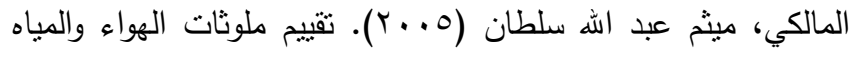

والتربة في مدينة بغداد باستخدام نظام المعلومات الجغرافية

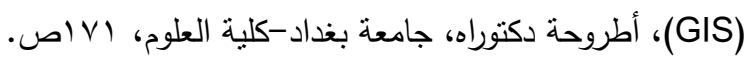

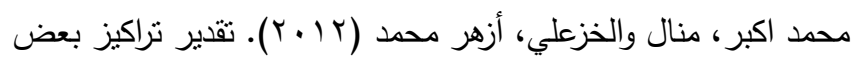

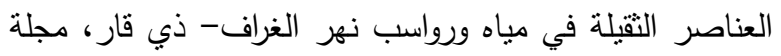

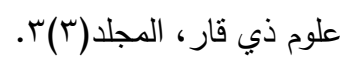

Al-Baidhany, A. H. (2013). Geochemical Assessment of Trace Element in Core Sediments from Hor Al-Ezaim, Southern Iraq. Department of geology, College of Science, University of Basrah. p8.

Al-Saad, H. T.; Abd, I. A.; Al-Hello, M. A., and Zuhkair, M. K., (2007). Environmental Assessment of trace metals pollution in sedimsnt of Khor Al-Zubair, Marina mesipotamica,22(1):81-92.

Al-Saad, H.T., Abd,I.A., Al-Hello, M.A. and Zukhair, M.K. (2006). Environmental Assessment of trace metal pollution in sediment of Khor al-Zubair, Iraq . Marine Mesopot. 21 (2) : 23-33.

Al-Sabah, B. J.(2013). Assessment of Sediment Quality Collected from AL-Hawizeh Marsh, Southern Iraq, Marsh Bulletin, Vol8(1), 27-38.

ASTM, (2007). American society for testing and material. International Standard for heavy metals in soil. www. fftc. Agent. Org/ library/149.

Chester, R. and Voutsinou, F. G. (1981). An approach to the assessment of local trace metal pollution in the Mediterranean marine atmosphere, Marine Pollution Bulletin, Vol. 12 , No. 3, pp 84-91.

Kabata- Pendias (2011). Trace elements in the Soil and Plants. 4th ed CRC Press. 469p.

Kadhim, L. S.; Salih, S. A. and Qadir, M. (2010). Soil Contamination by Heavy Metals in Floodplain of
تلوث عالي بالعناصر الثقلة كالحديد والمنغنيز والنيكل والنحاس والزنك والكوبلت والرصاص بأسنثناء عنصر الكادميوم الذى اعطى درجة تلوث

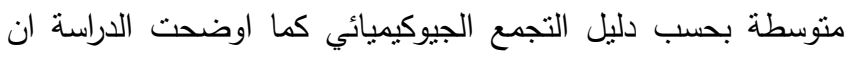
العامل الرئيس المؤثر في زيادة تراكيز بعض العناصر الثقيلة في نربة لئي

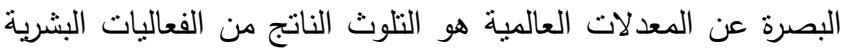
المختلفة والعمليات الصناعية فضلا عن طبيعة الصخور المصدرية المكونة لهذه التربة.

References المصادر: البصام، خلدون صبحي (11) • (1). العوامل البيئية المؤثرة في التوزيع المكاني للكادميوم في رواسب نهر الفرات في العراق، مجلة

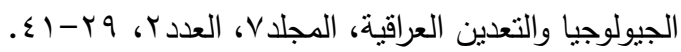

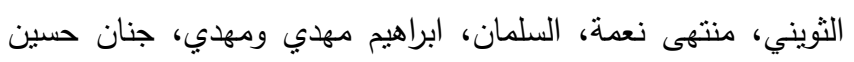

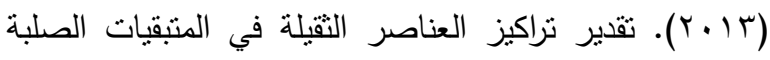
وغبار الارصفة من شوارع مدينة بغداد، مجلة ابن الهيثم للعلوم

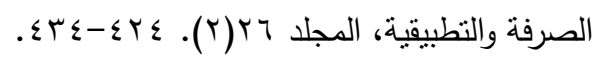

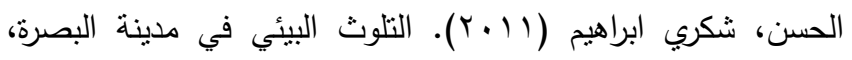
أطروحة دكتوراه، قسم الجغراقية، تخصص بئئة وتلوث، كلية لئل

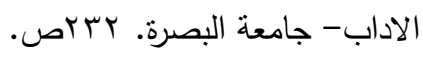

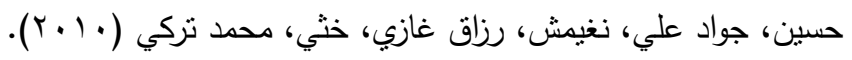

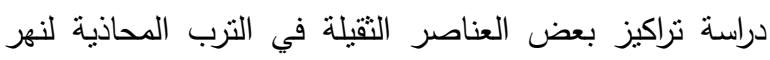

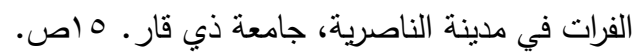

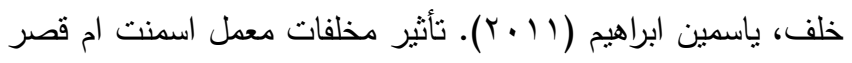
في خصائص التربة وتلوثها بالعناصر الثقيلة، اطروحة ماجسنير

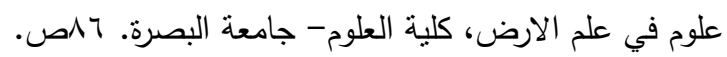
سلطان، ميثم عبداله، الربيعي، مهدي صالح وضئ وعصام عبدالرحيم

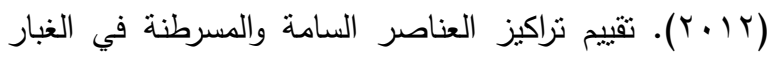

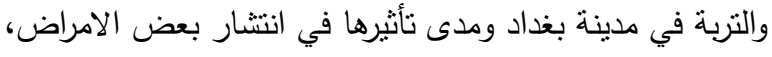

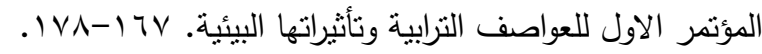

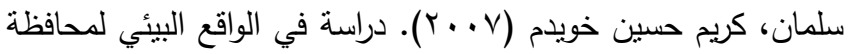

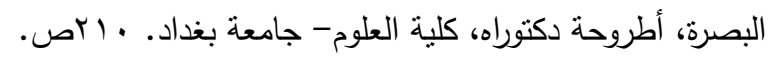

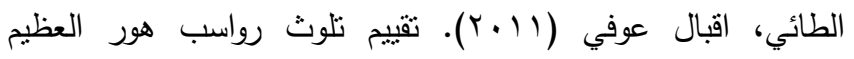

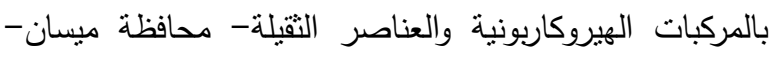
جنوب العراق، اطروحة ماجستير علوم في علم الارض.

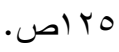


Qweik River, Aleppo, Syria, Tikrit Journal of Pure Science 16 (4): 1813-1662.

Mireles F, Davila JI, Pinedo JL, Reyes E, Speakman RJ, Glascock MD (2012). Assessing urban soil pollution in the cities of Zacatecas and Guadalupe, Mexico by instrumental neutron activation anal-ysis Microchem J 103:158-164.

Moore, J.W. and Ramamoorthy, S. (1984),Heavy metals in natural waters, applied monitoring and impact assessment. Springer-Verlag, New York, pp:286.

Muller, G. (1979). Schwermetalle in den Sedimenten des Rheins:( Veranderun genseit. Umschav, 79: 133-149.

Page , E. R. ; Miller, R. H. and Kenny, D. R. (1982). Methods of soil analysis, Part 2, 2nd ed. Agron. 9.

Preer, J. R., Sekhon, H. S., and Stevens, B. R. (1980). Environmental Pollution. Ser., 1, 95-104.

Raaheem, A. Z. (2009). Distribution of Heavy metals in Sediments of North Zone Basrah Governate. Marsh Bulletin 4(175-84.

Sarvides, C.; Papadopoulos, A.; Haralambous, K.S. and Loizidon, M. (1995). Sediment contaminated with heavy metals: Metal speciation and removal. Water Science Tech., 32(9-10): 65-73.

Sturgeon, R. E., Desaulincrs, J.A., Berman, S.S. and Russell, D.S. (1982). Determination of trace metals in estuarine sediments by graphic furnace atomicabsorption spectrophotometry. Anal Chem. Acta., Vol.134, pp.288-291.

Sultan, A. W. A.; Alhello, A. A.; Aribi, M. A. and AlSaad, H. T. (2013). Assessment of hydrocarbons and trace metalspollution in water and sediments of the Fertilizer Plant wastes in Khor Al-Zubair, Iraq. Mesopot. Journal Marine Science, 28(1): 17 -28 .

Wilda, A. M. (1993). Environment- Cambridge University Press, 1, pp.89-210.

Yaylal1-Abanuz G (2011) Heavy metal contamination of surface soil around Gebze industrial area, Turkey. Microchem J. 99(1):82-92. 